\title{
Substance dependence treatment endpoint and intermediate outcomes
}

\begin{abstract}
This min review identified the plethora of published substance dependence treatment outcomes between 2012 and 2017 and classified them with reference to their treatment foci. The reviewed papers were original and review articles indexed in PubMed. The endpoint outcome was identified as highest attainable level of health and well-being. The intermediate outcomes leading to the endpoint were identified as primary and secondary.
\end{abstract}

Keywords: substance, dependence, treatment, outcome, measure
Volume 3 Issue 2 - 2017

\author{
Peter Olutunde Onifade \\ Drug Addiction Treatment Education and Research Unit, Nigeria \\ Correspondence: Peter Olutunde Onifade, Drug Addiction \\ Treatment Education and Research Unit, Neuropsychiatric \\ Hospital, Arso, Abeokuta, Nigeria, Tel 2348035061082, \\ Email oniffpo@yahoo.com
}

Received: January 31, 2017| Published: April II, 2017
Abbreviations: WHO, world health organization; SRBT, selfreport and/or biological testing; SUD, substance use disorders

\section{Introduction}

Substance dependence is a clinical disorder resulting from repeated, excessive use of psychoactive substance that affects the brain to alter mental processes, namely thinking, feeling, perception and behavior. The associated problems of substance dependence are mediated via direct and indirect effects of the substance on physical and mental health and via the effects of altered mental processes on personal functioning that spills over to impairment in family and broader social context.

The etiology of the disorder is complex because problems associated with it may stem from, lead to, aggravate, or may not have direct cause-effect relationship to it. This complexity informs the treatment foci and expected outcomes in substance dependence treatment. Many investigators of Substance dependence treatment have reported a plethora of outcome measures. The aim of this mini review was to identify and classify treatment outcome measures for substance dependence.

A systematic search of PubMed was conducted on 6 March 2017. The advanced query builder of PubMed was used to search articles that contained the following query in their titles: (Substance or drug) and (use or abuse or dependence or addiction or hazardous) and (treatment or intervention) and (outcome* or goal* or measure* or aim* or result*). The asterisk (*) truncation "wildcard" was added to search the plural forms of the corresponding keywords. The search query resulted in 329 hits. Papers published outside the last 5 years were excluded, giving final hits of 78 papers. The abstracts of the papers were perused and those found relevant (that is contained reference to outcome measures) were retrieved and reviewed in detail. When multiple articles report on same outcome, the most recent or most relevant was cited. Some articles in the reference lists of the reviewed article were also retrieved and reviewed. As the foundation for outcome for any health intervention, the World Health Organization document that defines the scope of any treatment and its outcome was included for review along with the papers selected.

\section{Discussion}

According to WHO Expert Committee on substance dependence, treatment is used to define the process that begins when psychoactive substance users come into contact with a health provider or other community service, and may continue through a succession of specific interventions until the highest attainable level of health and wellbeing is reached. ${ }^{1}$ Strictly by this definition, a successful treatment gives "highest attainable level of health and well-being", which is the overall goal but which, with presently available assessment tools and techniques, is impracticable to measure. However, there are tools to measure increase in "level of health and well-being"; for example, Addiction Severity Index ${ }^{2}$ can measure changes in level of physical, mental and social health while a visual analogue scale can do the same for well-being. ${ }^{3}$

Since treatment is a "succession of specific interventions", all specific interventions have goals that contribute to the overall goal. For individuals currently using substance, the first goal of intervention is to increase their motivation (and get them to the point of taking action) to stop or reduce their substance use. This can be achieved with Screening Brief Intervention and Referral for Treatment ${ }^{4}$ and can be assessed with instruments such as Readiness Ruler $^{5}$ or the Stages of Change, Readiness, and Treatment Eagerness Scale. ${ }^{6}$ For individuals receiving or who have received treatment, stopping or reducing substance use is often taken as the primary treatment outcome and is assessed with self-report and/or biological testing (SRBT). ${ }^{7-9}$ Having stopped or reduced substance use, the outcome of treatment becomes maintenance or relapse prevention, ${ }^{6}$ which is also measured with SRBT. Stopping, reducing or relapse prevention is recommended as primary outcome of treatment. "Primary" in this sense is not necessarily the "most important" for all patients with substance use disorders (SUD) every time they access treatment for SUD; it should be taken as meaning without substance use, the patient would not present in a SUD treatment facility. Treatment related predictors of abstinence or reduced substance use, such as treatment retention, ${ }^{2}$ endorsement of the philosophy and behaviors encouraged in 12-step oriented drug counseling ${ }^{10}$ and patient satisfaction with treatment ${ }^{11}$ are also published treatment outcomes. Other outcomes include behavioral attributes such as externalizing and internalizing tendencies ${ }^{12}$ and risky behaviours, such as injection risk and high-risk sexual behaviors. ${ }^{13}$ A treatment outcome that is focused on monetary value is the economic gain of treatment against non-treatment. ${ }^{14}$

\section{Conclusion}

While "highest attainable level of health and well-being" is the two-pronged endpoint outcome of substance dependence treatment, 
intermediate outcomes which lead to the endpoint may be classified as primary outcome, that is, those related to cessation or reduction in quantity or frequency of substance use; and secondary outcomes, such as predictors of substance use reduction or abstinence, amelioration of aspect(s) of the multi-domain problems associated with substance dependence, and economic value of treatment against non-treatment. Specific interventions in substance abuse treatment focus on specific intermediate outcomes. The complexity of substance dependence and its treatment makes it necessary to consider many outcome measures when evaluating treatment and to link specific interventions with specific outcomes.

\section{Acknowledgements}

None.

\section{Conflict of interest}

The author declares no conflict of interest

\section{References}

1. World Health Organization (WHO) WHO Expert Committee on Drug Dependence. WHO Technical Report Series 873, Thirtieth Report. Geneva, Switzerland, 1998. p. 1-50.

2. Chartier KG, Carmody T, Akhtar M, et al. Hispanic Subgroups, Acculturation, and Substance Abuse Treatment Outcomes. J Subst Abuse Treat. 2015;59:74-82.

3. Tirado-Muñoz J, Gilchrist G, Lligoña E, et al. A group intervention to reduce intimate partner violence among female drug users. Results from a randomized controlled pilot trial in a community substance-abuse center. Adicciones. 2015;27(3):168-178.

4. McCance-Katz EF, Satterfield J. SBIRT: a key to integrate prevention and treatment of substance abuse in primary care. Am $J$ Addict. 2012;21(2):176-177.

5. Korcha RA, Cherpitel CJ, Moskalewicz J, et al. Readiness to change, drinking, and negative consequences among Polish SBIRT patients. Addict Behav. 2012;37(3):287-292.
6. Myers B, Van Der Westhuizen C, Naledi T, et al. Readiness to change is a predictor of reduced substance use involvement: findings from a randomized controlled trial of patients attending South African emergency departments. BMC Psychiatry. 2016;16(1):35 p.

7. Crits Christoph P, Markell HM, Gallop R, et al. Predicting outcome of substance abuse treatment in a feedback study: Can recovery curves be improved upon? Psychother Res. 2015;25(6):694-704.

8. Donovan DM, Bigelow GE, Brigham GS, et al. Primary outcome indices in illicit drug dependence treatment research: systematic approach to selection and measurement of drug use end-points in clinical trials. Addiction. 2012;107(4):694-708.

9. Rohsenow DJ, Martin RA, Tidey JW, et al. Comparison of the cigarette dependence scale with four other measures of nicotine involvement correlations with smoking history and smoking treatment outcome in smokers with substance use disorders. Addict Behav. 2013;38(8):24092413.

10. Patkar AA, Thornton CC, Berrettini WH, et al. Predicting treatmentoutcome in cocaine dependence from admission urine drug screen and peripheral serotonergic measures. $J$ Subst Abuse Treat. 2002;23(1):3340.

11. Kendra MS, Weingardt KR, Cucciare MA, et al. Satisfaction with substance use treatment and 12-step groups predicts outcomes. Addict Behav. 2015;40:27-32.

12. Hogue A, Dauber S, Liddle HA, et al. Linking Session Focus To Treatment Outcome In Evidence-Based Treatments For Adolescent Substance Abuse. Psychotherapy (Chic). 2004;41(2):83-96.

13. Murphy DA, Brecht ML, Herbeck D, et al. Longitudinal HIV risk behavior among the Drug Abuse Treatment Outcome Studies (DATOS) adult sample. Eval Rev. 2008;32(1):83-112.

14. Ettner SL, Huang D, Evans E, et al. Benefit-cost in the California treatment outcome project: does substance abuse treatment \&quot;pay for itself \& quot? Health Serv Res. 2006;41(1):192-213. 